\title{
Usefulness of carotid ultrasonography in the diagnosis of coronary artery disease in patients undergoing exercise echocardiography
}

\author{
Raúl Franco-Gutiérrez ${ }^{1 *} \mathbb{D}$, Alberto José Pérez-Pérez , Virginia Franco-Gutiérrez², Ana María Testa-Fernández', \\ Rafael Carlos Vidal-Pérez', Manuel Lorenzo López-Reboiro, Víctor Manuel Puebla-Rojo', Melisa Santás-Álvarez', \\ María Generosa Crespo-Leiro ${ }^{4,5,6}$ and Carlos González-Juanatey ${ }^{1}$
}

\begin{abstract}
Background: Relationship between carotid and coronary artery disease (CAD) in patients undergoing invasive and non-invasive test is unclear. The aim of the study is to evaluate whether carotid disease is associated with CAD in patients submitted to exercise echocardiography (EE) and if it improves the EE ability to predict CAD.

Methods: We retrospectively studied 156 subjects without previous vascular disease who underwent EE, carotid ultrasonography and coronary angiography between 2002 and 2013. Positive EE was defined as exercise induced wall motion abnormalities, carotid disease according to Manheim and American Society of Echocardiography Consensus and significant CAD as stenosis $\geq 50 \%$.
\end{abstract}

Results: Eighty-nine (57.1\%) subjects had significant CAD. Factors associated with CAD in multivariate analysis were fasting plasma glucose (odds ratio $[O R] 1.02, p=0.031$ ), pre-test probability of $C A D>65 \%$ (OR 3.71, $p<0.001$ ), positive EE (OR 10.51, $p<0.001)$ and carotid plaque (CP) presence (OR 2.95, $p=0.013)$. There was neither statistical significant difference in area under the curve after addition of CP to EE results $(0.77$ versus $0.81, p=0.525)$ nor sensitivity, specificity, predictive values or efficiency. CP presence reclassified as very high-risk according to Systematic COronary Risk Evaluation 13 patients (34.2\%) with negative EE and 22 (33.3\%) without CAD.

Conclusion: $C P$ is associated with $C A D$ in patients undergoing $E E$, however its addition to EE does not improve CAD prediction, probably due to insufficient statistical power. CP reclassified one third of patients to very high-risk category despite negative EE or CAD absence, these subjects benefit from aggressive primary prevention interventions.

Keywords: Stress echocardiography, Exercise test, Carotid artery disease, Coronary artery disease, Area under curve

\section{Background}

Ischaemic heart disease is a major problem due to its prevalence, health cost and mortality [1-3]. Stress echocardiography is a well-validated tool for diagnosis and risk stratification in patients with new onset chest pain, but it has some limitations that can impair its diagnostic capacity such as the dependence of pre-test probabilities

\footnotetext{
* Correspondence: raul.franco.gutierrez@sergas.es; raulfrancogutierrez@yahoo.es

'Department of Cardiology, Hospital Universitario Lucus Augusti (HULA), Avenida doctor Ulises Romero $n^{\circ}$ 1, 27003 Lugo, Spain

Full list of author information is available at the end of the article
}

(PTP) of coronary artery disease (CAD), the need to achieve submaximal heart rate, the presence of suboptimal echocardiographic windows, the inability to detect non limiting flow coronary stenosis or pathologies that can produce wall motion abnormalities during exercise [2-4].

Carotid disease, defined as increased carotid intima-media thickness (CIMT) or the presence of atherosclerotic plaques $(\mathrm{CP})$, has been associated with myocardial infarction, stroke and death [5-7]. Post-mortem studies have also demonstrated a correlation between carotid and CAD [8]. These findings encouraged 
investigators to evaluate the possibility of using carotid disease in the diagnosis of CAD of patients undergoing invasive and non-invasive tests, however the studies published so far have shown inconsistent results [9-19]. In that sense a meta-analysis of 34 studies focused on the relation of CIMT with coronary atherosclerosis, 30 showed a positive but modest relationship with correlation positive coefficients between 0.12 and 0.51 with only one study being above 0.5 and some studies showed no relationship at all [19].

Our group has broad experience in the ultrasonographic assessment of carotid arteries, having demonstrated its usefulness as a marker of subclinical atherosclerosis in subjects with autoimmune diseases [20]. The studies mentioned before [5-8], along with our findings, led to the systematic use of carotid ultrasound in subjects with suspected CAD undergoing exercise echocardiography (EE) at our cardiovascular imaging laboratory since 2002. This approach has been endorsed by the European Society of Cardiology (ESC) stable CAD guidelines as a IIa level C recommendation [2].

A clinical study was designed to evaluate if carotid disease is associated with significant CAD in patients with suspected ischaemic heart disease undergoing treadmill exercise stress echocardiography at our institution and if it improves the EE ability to predict significant CAD.

\section{Methods}

\section{Study population}

Between Jan. 1st 2002 and Dec. 31st 20134024 consecutive Caucasian subjects older than 18 years with suspected CAD underwent EE and carotid ultrasonography at our institution. Of them, 390 patients (9.7\%) were also submitted to a coronary angiography. 234 patients $(60 \%)$ were excluded: 29 (7.4\%) due to prior stroke, transient ischaemic attack or peripheral artery disease and 205 due to prior CAD (52.6\%) defined as previous myocardial infarction [21], coronary revascularization or angiographic documentation of any coronary stenosis $\geq 50 \%$. All patients signed informed consent before testing. The study was approved by the Regional Ethics Committee.

Demographic, clinical, baseline echocardiography, carotid ultrasonography and stress testing data were collected. PTP of CAD and Systematic COronary Risk Evaluation (SCORE) were assessed according to current ESC guidelines [1, 2].

\section{Treadmill exercise stress echocardiography}

Treadmill exercise was the stress modality chosen using a Philips Sonos 5500 ultrasound machine between 2002 and 2005 and a Philips iE33 after 2005 (Philips Medical Systems).

Heart rate, blood pressure and 12-lead electrocardiogram were obtained at baseline and at each exercise stage. EE was finished in case of physical exhaustion, disabling chest pain, significant arrhythmia and severe hypertensive or hypotensive response. Apical long-axis, apical 4- and 2-chamber and parasternal long- and short-axis views were obtained at rest, peak and immediately after exercise. Echocardiographic analysis was performed using a 17-segment model of the left ventricle to evaluate regional wall motion. Each segment was graded on a 4-point scale depending on its motion. Wall motion score index was calculated as the sum of the scores divided by the number of segments at rest and at peak exercise.

Ischaemic electrocardiographic abnormalities were defined as development of ST-segment deviation $80 \mathrm{msec}$ after J point $\geq 1 \mathrm{~mm}$. Echocardiographic ischaemia was defined as exercise induced new or worsening wall motion abnormalities, except worsening from akinesia to dyskinesia and isolated hypokinesia of the inferobasal segment. Extensive ischemia was defined as ischaemia involving $\geq 3$ myocardial segments and multivessel ischemia as ischemia involving $\geq 2$ different coronary territories [4].

\section{Carotid ultrasonography}

Carotid scans were performed immediately after stress testing in the same EE ultrasound equipment using a high-resolution, B-mode ultrasound system with a linear array $(3-11 \mathrm{MHz})$ transducer. Measurement of the CIMT and CP definition were done following the ARIC protocol study [5] and expert consensus [22-25]. Semi-automated edge detection software was used (QLAB; Philips 110 Medical Systems, Andover, MA, USA).

Age- and sex-specific CIMT percentile values were obtained from previously published data in our country [26].

Both EE and carotid ultrasonography stored images were analysed by two imaging expert cardiologists blinded to angiography results. In case of disagreement a third expert was consulted.

\section{Coronary angiography}

The physician in charge of the patient carried out a coronary angiography considering the results of the EE and other conditions such as persistence of symptoms despite optimal medical treatment, patients' preferences and/or other clinical criteria. Coronary angiography was performed using standard technique. Significant angiographic disease was defined as stenosis $\geq 50 \%$ by visual assessment in any major epicardial arteries or in their branches.

Coronary angiography analysis was similar to ultrasonography. 


\section{Statistical analysis}

Categorical variables were reported as percentages and comparison between groups were based on chi-square or Fisher's exact tests. Continuous variables were reported as mean (standard deviation) or median [interquartile range] when their distribution departed from normal and differences were assessed via the unpaired $t$ test or the Mann-Whitney $U$ test where appropriate. Binary and continuous quantitative variables were compared using logistic binary regression. To create predictive models for the presence of significant CAD, backward stepwise binary logistic regression was used with an entry set at 0.2 significance level and a retention set of 0.1 . A $p$ value of $<0.05$ was considered statistically significant. ! DT V2009.06.26 ${ }^{\circ}$ macro for SPSS Statistics (Autonomous University of Barcelona) and IBM SPSS Statistics for Windows, Version 20.0. (Armonk, NY) was used to calculate sensitivity, specificity, positive (PPV) and negative predictive values (NPV), positive (PLR) and negative likelihood ratios (NLR) and efficiency of EE alone and combined with carotid ultrasonography. Area under the curve (AUC) was calculated by means of a receiver operating characteristic curve analysis; comparison between AUC was done by the DeLong method.

\section{Results}

One hundred fifthy six patients were enrolled in the study. Mean age was 66.1 \pm 10.4 years and $102(65.4 \%)$ were men. There were no major complications during or after the tests.

Baseline characteristics are summarized in Table 1.

\section{Prediction of CAD}

Mean time between non-invasive tests and coronary angiography was 4.2 (3.2) months. Of the 156 patients $89(57.1 \%)$ had significant CAD. This subgroup was older ( $p=0.045)$, with male predominance $(p=0.011)$, had more frequently diabetes mellitus (DM), smoking habit $(p=0.023)$ and higher levels of fasting plasma glucose (FPG) $(p=0.003)$. Higher SCORE, PTP of CAD as well as positive EE and CP presence (all of them $p<0.001$ ) were also significantly more frequent in patients with CAD.

In multivariate analysis FPG $(p=0.031)$, PTP $>65 \%$ $(p<0.001)$, positive EE $(p<0.001)$ and CP $(p=0.013)$ were predictors of significant CAD.

Comparisons of subgroups with and without significant CAD and multivariate analysis are represented in Tables 2 and 3 respectively.

Regarding the subgroup of 21 (13.6\%) subjects with resting wall motion abnormalities 4 (19\%) had global left ventricular hypokinesia. Of the 21 patients 17 (81.0\%) developed worsening wall motion abnormalities during $\mathrm{EE}$ and all of them showed significant CAD in the angiography, 2 (9.5\%) were defined as negative EE and did not have significant CAD and 2 (9.5\%) could not achieve submaximal predicted heart rate, both without significant CAD in the angiography.

\section{AUC, sensitivity, specificity, predictive values, PLR and NLR and efficiency}

AUC of EE alone was 0.77 (95\% confidence interval [CI] 0.68-0.86), whereas AUC combining CP findings was $0.81(95 \%$ CI $0.70-0.92)(p=0.525)$. Results are summarized in Fig. 1 and Table 4.

Sensitivity, specificity, predictive values, PLR and NLR and efficiency of EE alone and EE combined with CP are also summarized in Table 4. Table 5 shows predictive values according to established intermediate PTP.

\section{SCORE reclassification according to carotid ultrasound}

According to European guidelines on cardiovascular disease prevention [1] 10 subjects $(6.4 \%)$ had low-risk at the time of EE, 52 (33.3\%) had moderate-risk, 47 (30.1\%) had high-risk, 45 (28.8\%) had very high-risk and 2 patients $(1.3 \%)$ could not be classified. When carotid ultrasonography findings were applied 59 patients $(37.8 \%)$ were reclassified as very high-risk according to $\mathrm{CP}$ presence. Focusing in the 62 patients with low or moderate SCORE risk, 28 (45.2\%) had CP.

Of the 38 patients with negative EE 5 subjects (13.2\%), 16 (42.1\%), 10 (26.3\%) and 7 (18.4\%) had low, moderate, high and very high-risk respectively. Considering $\mathrm{CP}$ presence 13 patients (34.2\%) were reclassified as very high-risk. Regarding the 21 patients with low or moderate SCORE risk and negative EE, 7 (33.3\%) had CP being thereby considered as very high-risk.

Finally, of the 67 patients without CAD, 9 subjects (13.4\%) had low-risk, 28 (41.8\%) had moderate-risk, 19 (28.4\%) had high-risk, 10 (14.9\%) had very high-risk and 1 (1.5\%) could not be classified. Considering CP results, 22 patients $(33.3 \%)$ were classified as very high-risk despite normal angiography. Of the 37 patients without significant CAD initially classified as low or moderate SCORE risk 12 (32.4\%) presented CP.

\section{Discussion}

This study correlates carotid disease with CAD in a real life cohort of patients without prior vascular disease undergoing EE. However, its addition to stress test does not improve CAD prediction by angiography. It is necessary to highlight the fact that nearly one third of patients with negative $\mathrm{EE}$ and without $\mathrm{CAD}$ are reclassified to high-risk group according to carotid ultrasonography findings.

Akosah et al. [13] found an association between carotid (CP or maximal CIMT $\geq 1 \mathrm{~mm}$ ) and CAD in 236 patients referred for elective coronary angiography with a high NPV in case of both negative tests. However, only 
Table 1 Baseline characteristics of patients

\begin{tabular}{|c|c|}
\hline & $\begin{array}{l}\text { Non-prior vascular disease } \\
(n=156)\end{array}$ \\
\hline Age (years) & $66.1(10.4)$ \\
\hline Male sex (\%) & $102(65.4 \%)$ \\
\hline Body mass index $\left(\mathrm{Kg} / \mathrm{m}^{2}\right)$ & $28.7(4.0)$ \\
\hline Hypertension & $93(59.6 \%)$ \\
\hline Hypercholesterolemia & $91(58.3 \%)$ \\
\hline $\mathrm{DM}$ & $41(26.3 \%)$ \\
\hline Smoking habit & $68(43.6 \%)$ \\
\hline Family history of premature CAD & $22(14.1 \%)$ \\
\hline \multicolumn{2}{|l|}{ SCORE } \\
\hline Low & $10(6.4 \%)$ \\
\hline Moderate & $52(33.3 \%)$ \\
\hline High & $47(30.1 \%)$ \\
\hline Very high & $45(28.8 \%)$ \\
\hline Chest pain & $149(95.5 \%)$ \\
\hline Typical & $82(55.0 \%)$ \\
\hline Atypical & $65(43.6 \%)$ \\
\hline Non-anginal & $2(1.3 \%)$ \\
\hline FPG levels (mg/dL) & $114.3(33.5)$ \\
\hline $\mathrm{GFR}\left(\mathrm{ml} / / \mathrm{min} / 1.73 \mathrm{~m}^{2}\right)$ & $78.3(24.0)$ \\
\hline Total Cholesterol levels (mg/dL) & $189.2(44.7)$ \\
\hline Low-density lipoprotein levels (mg/dL) & $114.4(38.5)$ \\
\hline High-density lipoprotein levels (mg/dL) & $44.1(11.7)$ \\
\hline Triglyceride levels (mg/dL) & $159.1(94.1)$ \\
\hline \multicolumn{2}{|l|}{ Drugs prior EE } \\
\hline Beta-blockers & $36(23.1 \%)$ \\
\hline Calcium channel blockers & $40(25.6 \%)$ \\
\hline Nitrates & $23(14.7 \%)$ \\
\hline Statins & $68(43.6 \%)$ \\
\hline Antiplatelet drugs & $51(32.7 \%)$ \\
\hline \multicolumn{2}{|l|}{ EE data } \\
\hline \multicolumn{2}{|l|}{ Systolic BP (mmHg) } \\
\hline Rest & $141.5(20.3)$ \\
\hline Peak & $184.9(29.3)$ \\
\hline \multicolumn{2}{|l|}{ Heart rate (beats/min) } \\
\hline Rest & $69.9(13.1)$ \\
\hline Peak & $131.6(18.6)$ \\
\hline \multicolumn{2}{|l|}{ Rate-pressure $\left(\times 10^{3} \mathrm{mmHg}\right.$ beats $\left./ \mathrm{min}\right)$} \\
\hline Rest & $9.9(2.5)$ \\
\hline Peak & $24.4(5.6)$ \\
\hline Exercise time (min) & $6.9(2.7)$ \\
\hline Positive EE & $93(59.6 \%)$ \\
\hline Negative EE & 38 (24.4\%) \\
\hline $\begin{array}{l}\text { Failure to achieve submaximal predicted } \\
\text { heart rate }\end{array}$ & $25(16.0 \%)$ \\
\hline
\end{tabular}

Table 1 Baseline characteristics of patients (Continued)

\begin{tabular}{ll}
\hline & $\begin{array}{l}\text { Non-prior vascular disease } \\
(n=156)\end{array}$ \\
\hline Metabolic equivalents & $7.5(2.6)$ \\
Left ventricular ejection fraction (\%) & $62.5(7.1)$ \\
$\quad$ Rest & $64.3(12.4)$ \\
Peak & $21(13.6 \%)$ \\
Resting wall motion abnormality & \\
Wall motion score index & $1.04(0.17)$ \\
$\quad$ Rest & $1.22(0.28)$ \\
Peak & \\
Carotid ultrasound data & $0.88(0.19)$ \\
Mean CIMT (mm) & \\
Mean CIMT percentile Spanish population & $18(11.5 \%)$ \\
$\quad \leq 25^{\text {th }}$ & $40(25.6 \%)$ \\
25 th - 75 & \\
$\geq 75^{\text {th }}$ & $98(62.8 \%)$ \\
CP & $95(60.9 \%)$ \\
Calcified CP & $47(30.5 \%)$
\end{tabular}

$B P$ Blood pressure, $C A D$ coronary artery disease, CIMT carotid intima-media thickness, $C P$ carotid plaque, $D M$ diabetes mellitus, $E E$ exercise echocardiography, FPG fasting plasma glucose, GFR glomerular filtration rate, SCORE European Systematic COronary Risk Evaluation

$162(68.6 \%)$ subjects had stress test performed (the type was not described in their study) with a low PPV (36\%) and also 95\%CI were not reported. Kanwar et al. [14] reported a study on 50 symptomatic patients without prior CAD who underwent coronary angiography after stress testing. CP, especially those with heterogeneous composition, irregular surface or calcification, was a predictor of significant CAD showing a NPV of $100 \%$ in patients with negative/equivocal stress test and $\mathrm{CP}$ absence. In contrast to our study, $28 \%$ were non-Caucasians and they used different modalities of stress imaging test with a high incidence (64\%) of equivocal results. Coskun et al. [15] identified hypertension and CIMT $\geq 1 \mathrm{~mm}$ as predictors of significant CAD in patients without previous CAD or stroke, scheduled for coronary angiography after a positive stress test. Similarly to Akosah et al. [13], the PPV of the stress test was lower compared to our results (61\%). Finally, Ahmadvazir et al. [16] identified PTP, positive stress test and presence of $\mathrm{CP}$ as predictors of significant CAD in 591 patients with suspected CAD undergoing stress echocardiography. As in previous studies, the NPV combining stress test and carotid ultrasonography was high $(80 \%)$ and, in agreement with our findings, nearly one third of the patients were reclassified for risk score according to $\mathrm{CP}$ results. However, only $35 \%$ of their patients were Caucasian, exercise as stress method was only used in $62 \%$ and only 83 (14\%) underwent coronary angiography and, similar to the other 
Table 2 Clinical, demographic, exercise and carotid ultrasound data in the subgroup of patients with and without CAD

\begin{tabular}{|c|c|c|c|}
\hline & $\begin{array}{l}C A D \geq 50 \% \\
(n=89)\end{array}$ & $\begin{array}{l}C A D<50 \% \\
(n=67)\end{array}$ & $p$ value \\
\hline Age & $67.6(9.2)$ & $64.1(11.6)$ & 0.045 \\
\hline Male sex & $66(74.2 \%)$ & $36(53.7 \%)$ & 0.011 \\
\hline Body mass index & $29.1(4.2)$ & $28.1(3.7)$ & 0.134 \\
\hline Hypertension & $55(61.8 \%)$ & $38(56.7 \%)$ & 0.621 \\
\hline Hypercholesterolemia & $56(62.9 \%)$ & $35(52.2 \%)$ & 0.193 \\
\hline DM & $31(34.8 \%)$ & $10(14.9 \%)$ & 0.006 \\
\hline Smoking habit & $46(51.7 \%)$ & $18(32.8 \%)$ & 0.023 \\
\hline Family history of early CAD & $14(15.7 \%)$ & $8(11.9 \%)$ & 0.643 \\
\hline FPG levels & $120.7(38.7)$ & $105.7(22.4)$ & 0.03 \\
\hline Total Cholesterol levels & $192.0(47.5)$ & $185.5(40.8)$ & 0.379 \\
\hline Low-density lipoprotein levels & $117.2(40.7)$ & $110.7(36.1)$ & 0.308 \\
\hline High-density lipoprotein levels & $43.0(11.3)$ & $45.6(12.1)$ & 0.168 \\
\hline Triglyceride levels & $160.6(91.1)$ & $157.2(98.7)$ & 0.824 \\
\hline GFR & $75.6(23.2)$ & $81.1(24.7)$ & 0.105 \\
\hline SCORE & & & $<0.001$ \\
\hline Low & $1(1.1 \%)$ & $9(13.6 \%)$ & \\
\hline Moderate & $24(27.3 \%)$ & $28(42.4 \%)$ & \\
\hline High & $28(31.8 \%)$ & 19 (28.8\%) & \\
\hline Very high & 35 (39.8\%) & $10(15.2 \%)$ & \\
\hline PTP of CAD & & & $<0.001$ \\
\hline$<15 \%$ & $0(0 \%)$ & $3(4.5 \%)$ & \\
\hline $15-65 \%$ & 31 (34.8\%) & $42(62.7 \%)$ & \\
\hline $65-85 \%$ & $55(61.8 \%)$ & $22(32.8 \%)$ & \\
\hline$>85 \%$ & $3(3.4 \%)$ & $0(0 \%)$ & \\
\hline Positive EE & $73(82.0 \%)$ & 20 (29.9\%) & $<0.001$ \\
\hline Mean CIMT (mm) & $0.88(0.21)$ & $0.89(0.18)$ & 0.926 \\
\hline $\mathrm{CIMT}>0.9 \mathrm{~mm}$ & $38(42.7 \%)$ & $31(46.3 \%)$ & 0.745 \\
\hline CIMT $>75^{\text {th }}$ percentile & $52(58.4 \%)$ & $46(68.7 \%)$ & 0.242 \\
\hline $\mathrm{CP}$ & $66(74.2 \%)$ & $29(43.3 \%)$ & $<0.001$ \\
\hline Calcified CP & $32(36.0 \%)$ & $15(22.4 \%)$ & 0.079 \\
\hline
\end{tabular}

PTP Pre-test probability. Rest of abbreviations as in Table 1

Table 3 Multivariate significant CAD analysis

\begin{tabular}{llllll}
\hline Variable & $B$ & $\begin{array}{l}p \\
\text { value }\end{array}$ & OR & & \multicolumn{2}{c}{$95 \% \mathrm{Cl}$} \\
\cline { 5 - 6 } & & & & Lower & Higher \\
\hline Constant & -4.83 & $<0.001$ & 0.01 & & \\
Smoking habit & 0.84 & 0.057 & 2.31 & 0.98 & 5.46 \\
FPG & 0.02 & 0.031 & 1.02 & 1.00 & 1.04 \\
PTP of CAD $>65 \%$ & 1.31 & 0.003 & 3.71 & 1.57 & 8.79 \\
Positive EE & 2.35 & $<0.001$ & 10.51 & 4.38 & 25.20 \\
CP & 1.08 & 0.013 & 2.95 & 1.25 & 6.93 \\
\hline C confidence interval, OR odds ratio. Rest of abbreviations as in Tables 1 and 2
\end{tabular}

$\mathrm{Cl}$ confidence interval, $\mathrm{OR}$ odds ratio. Rest of abbreviations as in Tables 1 and 2 studies [13-15], CI or comparison between AUC were not reported. In contrast with previous results, Sachpekidis [17] did not find any statistical association between carotid and CAD (defined as positive dobutamine stress test) in 130 patients, $43 \%$ of them with previous CAD. However, the study population was small with only $38.5 \%$ yielding positive results, prior CAD could have hampered its findings and there was no comparison with angiography.

Atherosclerosis is a systemic disease and it is likely that patients with carotid disease also have CAD. This fact, as previously mentioned, was demonstrated in post-mortem studies [8] and in Bots' meta-analysis [19]. The highly variability of the association, with a correlation range between $-0.04-0.51$ in the aforementioned meta-analysis, could be due to methodological differences in carotid ultrasound assessment and/or variability in atherosclerosis development between the vascular territories [19]. According to European and American guidelines on the management of stable CAD $[2,3]$ PTP of CAD must be established and then a non-invasive test must be performed for diagnostic or prognostic purposes depending on the degree of PTP. Both agree that a history of cerebrovascular or peripheral artery disease increases the likelihood of CAD [2, 3].

In our study most of the patients $(96.2 \%)$ had intermediate PTP and, most importantly, none of them had previous vascular or CAD. Predictors positively associated with significant $C A D$ were positive $\mathrm{EE}$ $(\mathrm{OR}=10.51), \mathrm{PTP}>65 \%(\mathrm{OR}=3.71), \mathrm{CP} \quad(\mathrm{OR}=2.95)$ and FPG levels $(\mathrm{OR}=1.02)$. It is interesting to mention that other important risk factors associated with CAD such as hypertension, hypercholesterolemia, cholesterol levels or smoking habit [1-3] were not significantly associated with CAD in our study, this fact can be explained due to insufficient statistical power and due to treatment effect, for example 42 patients $(47.2 \%)$ with significant CAD were taking statins at the time of EE performance while only 26 (38.8\%) of subjects without CAD were taking them, also $56(62.9 \%)$ subjects with significant CAD where on antihypertensive drugs compared to only 35 (52.2\%) of patients without CAD. FPG not DM was associated with CAD, the reason may be because the development of macrovascular disease occurs with insulin resistance, prior to DM diagnosis [27]; high or very high-risk SCORE was not also associated with CAD, probably because it is not designed to estimate it, just the risk of a fatal atherosclerotic event [1]. Although $\mathrm{CP}$ is the third in order in multivariable analysis after positive EE and PTP of CAD $>65 \%$, it increases by nearly 3 the likelihood of having significant CAD so carotid ultrasound could be useful in case of intermediate PTP, where diagnosis must be 


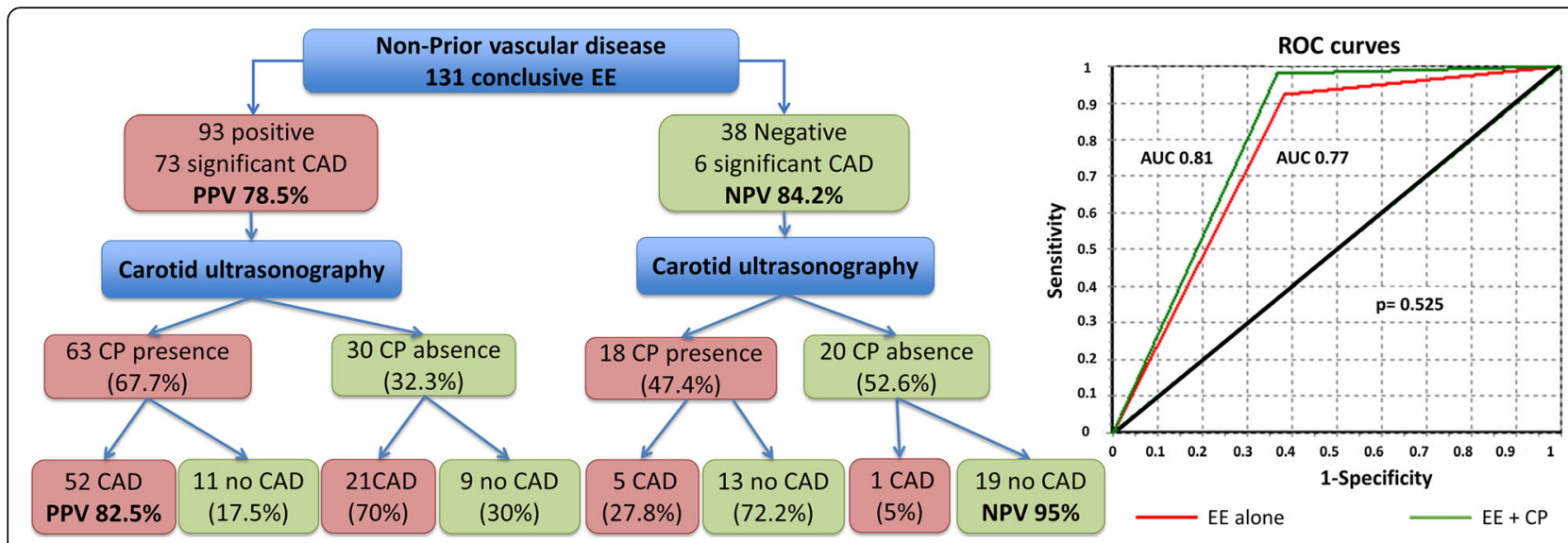

Fig. 1 Relationship between EE and CP and ROC curve representation. ROC: Receiver Operating Characteristic. Rest of abbreviation as in Tables 1 , 2,3 and 4

confirmed, or in equivocal EE. Moreover, and similar to Ahmadvazir et al. [16], CP presence reclassified around one third of patients to a high-risk category despite a negative EE or a normal coronary angiography. This is a very remarkable finding because these subjects benefit from aggressive primary preventive therapies [1] and, although ESC guidelines on cardiovascular disease prevention in clinical practice establish atherosclerotic plaque detection by carotid artery scanning in cardiovascular risk assessment as a IIb class level of evidence B recommendation [1], considering previously mentioned studies $[7,16]$ it might be changed to a IIa recommendation. Finally, although $\mathrm{CP}$ is associated with significant $\mathrm{CAD}$ its addition to EE did not improve AUC $(p=0.525)$, predictive values, efficiency and likelihood ratios due to CI overlap. These facts can be explained by insufficient statistical power, however it is important to mention the markedly but statistically non-significant increase in both NPV, especially in the moderate and high PTP of CAD groups, and in the NLR. These findings, although non-significant, are consistent to Kanwar et al. [14] and Ahmadvazir et al. [16] studies where CI were not reported. In this sense we considered our study only as hypothesis generating and increasing sample could corroborate it. Although there is a study addressing the utility of carotid ultrasonography for selecting patients who do not require coronary angiography before heart valve surgery [28], in our study $25.8 \%$ of patients with significant
CAD did not have $\mathrm{CP}$ and $43.3 \%$ of patients without significant $\mathrm{CAD}$ have $\mathrm{CP}$ in the carotid ultrasonography. For that reason we consider non-invasive stress test as the first line test in symptomatic patients with intermediate PTP and carotid ultrasonography as an additional tool for decision making. Unlike Kanwar et al. [14] we did not specifically analysed CP morphology, nevertheless we did not find significant association between calcified $\mathrm{CP}$ and significant $\mathrm{CAD}$, this fact can be related to insufficient sample size.

Our study has some limitations. First of all, it is a retrospective single institution study with a low recruitment rate and therefore it is hampered by the use of different equipments and methods of image storage. One alternative could be a multicentre prospective study. Secondly, not all subjects with exercise and carotid tests were submitted to angiography. As a consequence, there are few patients with a negative EE (24.4\%) in the sample and prevalence of CAD could be higher in our group than in the global population. Ideally, all subjects scheduled for EE and carotid ultrasonography should undergo angiography. However, it seems unethical to submit to an invasive, ionizing radiation exposing and expensive procedure asymptomatic people after optimal lifestyle and pharmacological management without bad-prognosis EE. Other important limitation is that the coronary artery stenosis percentage was assessed visually and not by using more accurate tools such as intravascular ultrasound or optical coherence tomography or by physiological

Table 4 Sensitivity, specificity, predictive values, AUC and likelihood ratios for CAD diagnosis

\begin{tabular}{|c|c|c|c|c|c|c|c|c|}
\hline \multicolumn{9}{|c|}{ Conclusive EE $(N=131)$} \\
\hline \multicolumn{9}{|c|}{$\frac{\text { Conclusive } \mathrm{EE}(N=131)}{\text { Sensitivity }(95 \% \mathrm{Cl})}$} \\
\hline$\overline{\mathrm{EE}}$ & $92.4 \%(84.4-96.5)$ & $61.5 \%(48.0-73.5)$ & $78.5 \%(69.1-85.6)$ & $84.2 \%(69.6-92.6)$ & $80.2 \%(72.5-86.1)$ & $0.77(0.68-0.86)$ & 2.40 & 0.12 \\
\hline $\mathrm{EE}+\mathrm{CP}$ & $98.1 \%(90.1-99.7)$ & $63.3 \%(45.5-78.1)$ & $82.5 \%(71.4-90.0)$ & $95.0 \%(76.4-99.1)$ & $85.5 \%$ (76.4-91.5) & $0.81(0.70-0.92)$ & 2.68 & 0.03 \\
\hline
\end{tabular}

AUC area under the curve, NLR negative likelihood ratio, NPV negative predictive value, PLR positive likelihood ratio, PPV positive predictive value. Rest of abbreviations as in Tables 1, 2 and 3 
Table 5 Predictive values for significant CAD prediction depending on its prevalence

\begin{tabular}{cll}
\hline Prevalence of CAD & PPV $(95 \% \mathrm{Cl})$ & NPV $(95 \% \mathrm{Cl})$ \\
\hline EE alone & & \\
$15 \%$ & $29.8 \%(23.0-37.6)$ & $97.9 \%(95.0-99.0)$ \\
$65 \%$ & $81.7 \%(75.9-86.4)$ & $81.4 \%(66.3-90.7)$ \\
$85 \%$ & $93.2 \%(90.6-95.1)$ & $58.8 \%(39.1-76.1)$ \\
EE + CP & & \\
$15 \%$ & $32.1 \%(22.8-43.1)$ & $99.5 \%(96.4-99.9)$ \\
$65 \%$ & $83.3 \%(75.6-88.9)$ & $94.8 \%(71.8-99.2)$ \\
$85 \%$ & $93.8 \%(90.4-96.0)$ & $85.6 \%(45.5-97.7)$ \\
\hline
\end{tabular}

Abbreviations as in Table 4

assessment of CAD stenosis in the cardiac catheterization laboratory (fractional flow reserve). This is a consequence of a retrospective study design, when some techniques were not available at the time of the angiography performance and it also reflects the usual clinical practice where intermediate stenosis are treated in case of a positive stress test and the methods mentioned before are used according to interventional cardiologist criteria, if negative or no stress test available. Comparison between carotid ultrasound and intracoronary imaging techniques in case of normal angiography could have helped to establish a better correlation between carotid and coronary artery disease, however the aim of the study was to find an association between carotid disease and significant and possibly flow limiting epicardial coronary stenosis causing chest pain. It is also important to keep in mind that this is a real life cohort study and using intravascular ultrasound or optical coherence tomography in people without intermediate CAD increases the cost and the duration of the procedure. Finally, there are $13.6 \%$ of patients with resting wall motion abnormalities, but we must consider that there are several conditions other than ischemic heart disease, such as cardiac sarcoidosis, myocarditis or cardiomyopathies that can also cause them.

\section{Conclusions}

In conclusion, our study shows that carotid disease, in particular the presence of $\mathrm{CP}$, is associated with significant CAD in patients submitted to EE. Its addition to EE does not improve sensitivity, specificity, predictive values, likelihood ratios, efficiency and AUC for significant CAD diagnosis; probably due to insufficient statistical power. However, CP reclassified one third of patients to very high-risk SCORE category despite a negative EE or CAD absence and these subjects benefit from aggressive primary prevention interventions.

\section{Abbreviations}

AUC: Area under the curve; BP: Blood pressure; CAD: Coronary artery disease; Cl: Confidence interval; CIMT: Carotid intima-media thickness; CP: Carotid plaque; DM: Diabetes mellitus; EE: Exercise echocardiography; ESC: European Society of Cardiology; FPG: Fasting plasma glucose; GFR: Glomerular filtration rate; NLR: Negative likelihood ratio; NPV: Negative predictive value; OR: Odds ratio; PLR: Positive likelihood ratio; PPV: Positive predictive value; PTP: Pre-test probability; ROC: Receiver Operating Characteristic; SCORE: European Systematic COronary Risk Evaluation.

\section{Acknowledgements}

The authors want to thank Miss Leonor Ortega Fernández for her assistance in data collection.

\section{Funding}

This research was supported by the "Fundación Ramón Domínguez para la Investigación, el Desarrollo y la Innovación biosanitaria", a non-profit foundation created by the merger of two Hospital Foundations: [Grant code ECOES].

\section{Availability of data and materials}

The datasets used and/or analyzed during the current study are available from the corresponding author on reasonable request.

\section{Author's contributions}

RFG (first author, corresponding author) and CGJ conceived and designed the research, RFG performed statistical analysis, CGJ handled funding and supervision, RFG, VFG, LOF and MLLR acquired the data, RFG, VFG and AJPP drafted the manuscript, all authors made critical revision of the manuscript for key intellectual content, and final approval of the manuscript submitted was done by CGJ and RFG. All authors read and approved the final manuscript.

\section{Ethics approval and consent to participate}

The study has been approved by the Regional Ethics committee: "Comité Territorial de Ética de Investigación de Santiago-Lugo" with the committee's reference number 2015/270, and have therefore been performed in accordance with the ethical standards laid down in the 1964 Declaration of Helsinki and its later amendments or comparable ethical standards.

\section{Consent for publication}

Not applicable.

\section{Competing interests}

The authors declare that they have no competing interests.

\section{Publisher's Note}

Springer Nature remains neutral with regard to jurisdictional claims in published maps and institutional affiliations.

\section{Author details}

${ }^{1}$ Department of Cardiology, Hospital Universitario Lucus Augusti (HULA), Avenida doctor Ulises Romero n 1, 27003 Lugo, Spain. ${ }^{2}$ Department of Otolaryngology, Hospital Universitario Marqués de Valdecilla, Avenida Valdecilla n²5, Santander 39008, Spain. ${ }^{3}$ Department of Internal Medicine, Hospital Universitario Lucus Augusti (HULA), Avenida doctor Ulises Romero n 1 , Lugo 27003, Spain. ${ }^{4}$ Department of Cardiology, Complejo Hospitalario Universitario A Coruña (CHUAC), As Xubias de Arriba nº 84, A Coruña 15006, Spain. ${ }^{5}$ Intitituto de Investigación Biomédica A Coruña (INIBIC), Xubias de Arriba n 84, A Coruña 15006, Spain. ' Universidad de La Coruña (UDC), Calle de la Maestranza n 9, A Coruña 15001, Spain.

Received: 30 July 2018 Accepted: 12 September 2018

Published online: 09 October 2018

\section{References}

1. Piepoli MF, Hoes AW, Agewall S, Albus C, Brotons C, Catapano AL, et al. 2016 European Guidelines on cardiovascular disease prevention in clinical practice: The Sixth Joint Task Force of the European Society of Cardiology and Other Societies on Cardiovascular Disease Prevention in Clinical Practice (constituted by representatives of 10 societies and by invited experts): Developed with the special contribution of the European Association for Cardiovascular Prevention \& Rehabilitation (EACPR). Eur Heart J. 2016;37:2315-81. 
2. Montalescot G, Sechtem U, Achenbach S, Andreotti F, Arden C, Budaj A, et al. 2013 ESC guidelines on the management of stable coronary artery disease: the task force on the management of stable coronary artery disease of the European Society of Cardiology. Eur Heart J. 2013;34:2949-3003.

3. Fihn SD, Blankenship JC, Alexander KP, Bittl JA, Byrne JG, Fletcher BJ, et al. 2014 ACC/AHA/AATS/PCNA/SCAI/STS focused update of the guideline for the diagnosis and management of patients with stable ischemic heart disease: a report of the American College of Cardiology/American Heart Association Task Force on Practice Guidelines, and the American Association for Thoracic Surgery, Preventive Cardiovascular Nurses Association, Society for Cardiovascular Angiography and Interventions, and Society of Thoracic Surgeons. J Am Coll Cardiol. 2014;64:1929-49.

4. Pellikka PA, Nagueh SF, Elhendy AA, Kuehl CA, Sawada SG. American Society of Echocardiography recommendations for performance, interpretation, and application of stress echocardiography. J Am Soc Echocardiogr. 2007;20:1021-41.

5. Chambless LE, Heiss G, Folsom AR, Rosamond W, Szklo M, Sharrett AR, et al. Association of coronary heart disease incidence with carotid arterial wall thickness and major risk factors: the atherosclerosis risk in communities (ARIC) study, 1987-1993. Am J Epidemiol. 1997;146:483-94.

6. Lorenz MW, Markus HS, Bots ML, Rosvall M, Sitzer M. Prediction of clinical cardiovascular events with carotid intima-media thickness: a systematic review and meta-analysis. Circulation. 2007;115:459-67.

7. Inaba Y, Chen JA, Bergmann SR. Carotid plaque, compared with carotid intima-media thickness, more accurately predicts coronary artery disease events: a meta-analysis. Atherosclerosis. 2012;220:128-33.

8. Iwakiri T, Yano Y, Sato Y, Hatakeyama K, Marutsuka K, Fujimoto S, et al. Usefulness of carotid intima-media thickness measurement as an indicator of generalized atherosclerosis: findings from autopsy analysis. Atherosclerosis. 2012;225:359-62.

9. Heuten H, Claeys M, Goovaerts I, Ennekens G, Bosmans J, Vrints C. Can measurement of the intima-media thickness of the carotid artery improve the diagnostic value of exercise stress tests? Acta Cardiol. 2006;61:501-5.

10. Schroeder B, Francis G, Leipsic J, Heilbron B, John Mancini GB, Taylor CM. Early atherosclerosis detection in asymptomatic patients: a comparison of carotid ultrasound, coronary artery calcium score, and coronary computed tomography angiography. Can J Cardiol. 2013;29:1687-94.

11. Teragawa H, Kato M, Kurokawa J, Yamagata T, Matsuura H, Chayama K. Usefulness of flow-mediated dilation of the brachial artery and/or the intima-media thickness of the carotid artery in predicting coronary narrowing in patients suspected of having coronary artery disease. Am J Cardiol. 2001;88:1147-51.

12. Nowak J, Nilsson T, Sylven C, Jogestrand T. Potential of carotid ultrasonography in the diagnosis of coronary artery disease: a comparison with exercise test and variance ECG. Stroke. 1998;29:439-46.

13. Akosah KO, McHugh VL, Barnhart SI, Schaper AM, Mathiason MA, Perlock PA, et al. Carotid ultrasound for risk clarification in young to middle-aged adults undergoing elective coronary angiography. Am J Hypertens. 2006;19:1256-61.

14. Kanwar M, Rosman HS, Fozo PK, Fahmy S, Vikraman N, Gardin JM, et al. Usefulness of carotid ultrasound to improve the ability of stress testing to predict coronary artery disease. Am J Cardiol. 2007;99:1196-200.

15. Coskun U, Yildiz A, Esen OB, Baskurt M, Cakar MA, Kilickesmez KO, et al. Relationship between carotid intima-media thickness and coronary angiographic findings: a prospective study. Cardiovasc Ultrasound. 2009;7:59.

16. Ahmadvazir S, Zacharias K, Shah BN, Pabla JS, Senior R. Role of simultaneous carotid ultrasound in patients undergoing stress echocardiography for assessment of chest pain with no previous history of coronary artery disease. Am Heart J. 2014;168:229-36.

17. Sachpekidis V, Bhan A, Paul M, Gianstefani S, Smith L, Reiken J, et al. The additive value of three-dimensional derived left atrial volume and carotid imaging in dobutamine stress echocardiography. Eur J Echocardiogr. 2011; 12:46-53.

18. Djaberi R, Schuijf JD, de Koning EJ, Rabelink TJ, Smit JW, Kroft L, et al. Usefulness of carotid intima-media thickness in patients with diabetes mellitus as a predictor of coronary artery disease. Am J Cardiol. 2009;104:1041-6.

19. Bots ML, Baldassarre D, Simon A, de Groot E, O'Leary DH, Riley W, et al. Carotid intima-media thickness and coronary atherosclerosis: weak or strong relations? Eur Heart J. 2007;28:398-406.

20. Gonzalez-Gay MA, Gonzalez-Juanatey C, Pineiro A, Garcia-Porrua C, Testa A, Llorca J. High-grade C-reactive protein elevation correlates with accelerated atherogenesis in patients with rheumatoid arthritis. J Rheumatol. 2005;32: 1219-23.
21. Thygesen K, Alpert JS, Jaffe AS, Simoons ML, Chaitman BR, White HD, et al Third universal definition of myocardial infarction. Circulation. 2012;126: 2020-35.

22. Stein $\mathrm{JH}$, Korcarz CE, Hurst RT, Lonn E, Kendall CB, Mohler ER, et al. Use of carotid ultrasound to identify subclinical vascular disease and evaluate cardiovascular disease risk: a consensus statement from the American Society of Echocardiography carotid intima-media thickness task force. Endorsed by the Society for Vascular Medicine. J Am Soc Echocardiogr. 2008;21:93-111 quiz 189-190.

23. Touboul PJ, Hennerici MG, Meairs S, Adams H, Amarenco P, Desvarieux M, et al. Mannheim intima-media thickness consensus. Cerebrovasc Dis. 2004; 18:346-9.

24. Touboul PJ, Hennerici MG, Meairs S, Adams H, Amarenco P, Bornstein N, et al. Mannheim carotid intima-media thickness consensus (2004-2006). An update on behalf of the advisory board of the 3rd and 4th watching the risk symposium, 13th and 15th European stroke conferences, Mannheim, Germany, 2004, and Brussels, Belgium, 2006. Cerebrovasc Dis. 2007;23:75-80.

25. Touboul PJ, Hennerici MG, Meairs S, Adams H, Amarenco P, Bornstein N, et al. Mannheim carotid intima-media thickness and plaque consensus (20042006-2011). An update on behalf of the advisory board of the 3rd, 4th and 5 th watching the risk symposia, at the 13th, 15th and 20th European stroke conferences, Mannheim, Germany, 2004, Brussels, Belgium, 2006, and Hamburg, Germany, 2011. Cerebrovasc Dis. 2012;34:290-6.

26. Grau M, Subirana I, Agis D, Ramos R, Basagana X, Marti R, et al. Carotid intima-media thickness in the Spanish population: reference ranges and association with cardiovascular risk factors. Rev Esp Cardiol (Engl Ed). 2012; 65:1086-93.

27. Low Wang CC, Hess CN, Hiatt WR, Goldfine AB. Atherosclerotic cardiovascular disease and heart failure in type 2 diabetes - mechanisms, management, and clinical considerations. Circulation. 2016;133:2459-502.

28. Belhassen L, Carville C, Pelle G, Monin JL, Teiger E, Duval-Moulin AM, et al. Evaluation of carotid artery and aortic intima-media thickness measurements for exclusion of significant coronary atherosclerosis in patients scheduled for heart valve surgery. J Am Coll Cardiol. 2002;39:1139-44.

\section{Ready to submit your research? Choose BMC and benefit from:}

- fast, convenient online submission

- thorough peer review by experienced researchers in your field

- rapid publication on acceptance

- support for research data, including large and complex data types

- gold Open Access which fosters wider collaboration and increased citations

- maximum visibility for your research: over $100 \mathrm{M}$ website views per year

At $\mathrm{BMC}$, research is always in progress.

Learn more biomedcentral.com/submissions 